\title{
Facilitating Spiritual Care for Whole Person Patient- Centered Care
}

\author{
Pamela H Cone* \\ Doctoral Nursing programs, Azusa Pacific University, USA
}

*Corresponding author: Pamela H Cone, Graduate \& Doctoral Nursing programs, School

of Nursing, Azusa Pacific University, USA.

Received Date: February 26, 2019

Published Date: March 12, 2019

\section{Opinion}

Spirituality is at the core of the person. When nurses care for the whole person, all domains of the person need to be addressed, including the spiritual [1,2]. There is a significant amount of research that indicates that addressing the deep inner needs of a patient will enhance healing [2-4]. While many nurses feel unprepared to facilitate spiritual care Cone PH, et al. [5], most recognize the importance in the overall healing process with their patients $[3,6,7]$.

This can result in an ethical dilemma for nurses, which, if left unresolved, can lead to burn-out and compassion fatigue [5,7]. However, when spiritual practices, including religious as well as non-religious approaches are utilized [8]. Nurses find that their connection to and rapport with their patients can be strengthened [3]. So, what are the steps or approaches that can facilitate spiritual care?

The first element is spiritual awareness. Nurses need to keep learning about spirituality and spiritual care competencies in order to become more comfortable and prepared to facilitate patient care in the spiritual domain [5,9]. When nurses are provided with spiritually focused readings and patient scenarios to reflect on, their thinking is expanded and they feel better prepared to face a variety of patient spiritual needs and concerns, and even patient spiritual resources [5]. One approach for increasing nurse preparation is to make spiritualty part of nursing education across the curriculum Mthembu TG \& Cone PH $[6,10]$; this can be done strategically by adding activities and assignments to current courses rather than adding a spirituality course to the overall curriculum [10]. Another approach is to promote nurse learning in the clinical setting among working nurses and students in practical clinical education $[4,9,10]$; pre- and post-conference meetings at shift change can be utilized if topics succinct and readings are brief.

The second element is spiritual assessment. Patient assessment needs to include cultural, religious, and spiritual beliefs, rituals, and practices Joanna Briggs \& Kessler C $[8,11]$ in order for nurses to identify what strengths can be accessed to assist the patient with healing. In addition, nurses can learn to recognize the spiritual cues the patient may give that can alert the nurse to a need that is deeply important to the patient [3]. Assessment must also address the cultural background, life view, and religion of patients in order to determine what spiritual approaches might be acceptable to the patient $[6,8]$. While some patients have religious beliefs, practices, and rituals that need to be supported by the nurse, others may have deeply held cultural beliefs and values that are not religious in nature $[1,4]$. Clear identification of both needs and resources is critically important to patient-centered care [7].

The third element is spiritual activities. Once a patient has been assessed and the needs and resources are identified, the nurse needs to activate the nursing team to work together to meet the patient concerns. This is actually the implementation phase of spiritual care [2]. If a patient is deeply religious and believes in prayer, the nurse can pray with the patient, or, if the nurse has no belief in prayer or a different way of praying, she or he can simply provide presence while the patient prays $[3,7]$. In addition, the hospital chaplain or priest, or the patient's own religious leader can be contacted to visit the patient [5]. If the nurse has preparation in particular mindfulness, meditation, or other spiritual or alternative practices that influence the spirit of the patient Kessler C \& Ramezani M [4,8], the nurse can ask the patient if he or she is willing to participate in the practice in order to promote rest, relaxation, and healing [7]. Following up with the patient and proceeding at the patient's pace are important elements of this aspect of facilitating spiritual care [3].

These three elements of spiritual care - spiritual awareness, spiritual assessment, and spiritual activities - are critical to the facilitation of spiritual care and the promotion of overall patient health and well-being. When applying the Nursing Process to these elements, it is clear that nurse awareness of the spiritual domain 
comes before the patient interaction; the patient focus begins with the spiritual assessment phase that includes assessment, diagnosis, goal setting, and planning while the spiritual activities phase includes the implementation, evaluation, follow-up, modification, and further follow-up as needed. These are all normal practices of nurses addressing the physiological domain, and even the psychological and social domains. However, whole person patientcentered care must include the spiritual domain. Nurses around the world recognize that the spiritual domain is important, but many lack the tools and/or competencies to facilitate care of the spirit. Therefore, nurse leaders need to provide learning opportunities for nurse relating to the spiritual domain and promote an open and accepting work environment where the spiritual needs of patients can be assessed and addressed.

\section{Acknowledgement}

None.

\section{Conflict of Interest}

Author declare no conflict of interest.

\section{References}

1. Cone PH (2016) Commentary on the importance of spiritual literacy. Christian Nurses International: Partnerships 1(7): 17-19.

2. Rykkje L, Eriksson K (2011) A qualitative metasythesis of spirituality from a caring science perspective. International Journal of Human Caring 15 (4): 40-53.
3. Giske T, Cone PH (2015) Discerning the healing path: How nurses assist patients spiritually in diverse health care settings. J Clinic Nurs 24(1920): 2926-2935.

4. Ramezani M, Ahmadi F, Mohammadi E, Kazemnejad A (2016) Catalysts to spiritual care delivery: A content analysis. Iranian Red Crescent Medical Journal 18(3): e22420.

5. Cone PH, Giske T (2017) Nurses' comfort level with spiritual assessment: A mixed method study among nurses working in diverse healthcare settings. J Clinic Nurs 26(19-20): 3125-3136.

6. Mthembu TG, Wegner L, Roman NV (2017) Barriers to integration of spirituality and spiritual care in occupational therapy education in a South African context. Journal of Spirituality in Mental Health 19(1): 6179.

7. Puchalski CM (2013) Integrating spirituality into patient care: An essential element of person-centered care. Polskie Archiwum Medycyny Wewnetrznej 123(9): 491-497.

8. Kessler C, Wischnewsky M, Michalsen A, Eisenmann C, Melzer J (2013) Ayurveda: Between religion, spirituality, and medicine. Evid Based Complement Alternat Med 2013: 952432.

9. Smith T, Gordon T (2009) Developing spiritual and religious care competencies in practice: Pilot of a Marie Curie blended learning event. Int J Palliat Nurs 15(2): 86-92.

10. Cone PH, Giske T (2018) Integrating spiritual care into nursing education and practice: Strategies utilizing open journey theory. Nurse Educ Today 71: $22-25$.

11. Joanna Briggs Institute (2010) The Joanna Briggs Institute Best Practice Information Sheet: The psychosocial and spiritual experiences of elderly individuals recovering from a stroke. Nurs Health Sci 12(4): 515-518. 